Gut, 1977, 18, 599-605

\title{
Effect of prolonged feeding with chenodeoxycholic acid on bile in patients with and without gallstones
}

\author{
M. C. BATESON, P. E. ROSS, J. MURISON, AND I. A. D. BOUCHIER \\ From the University Department of Medicine, Ninewells Hospital and Medical School, Dundee
}

SUMMARY Nineteen patients who received chenodeoxycholic acid $750 \mathrm{mg} /$ day for six months had duodenal bile aspirated before and after treatment. In five patients with hypertriglyceridaemia but no gallstones cholesterol saturation was reversed in every case, the mean cholesterol saturation index (SI \pm standard deviation) changing from $1.38 \pm 0.31$ to $0.68 \pm 0.06(\mathrm{P}<0.005)$. In 14 patients with gallstones there was also an improvement in bile cholesterol content, but this was not sufficient to produce mean unsaturation, saturation index changing from $1.55 \pm 0.52$ to $1.13 \pm 0.43$ $(P<0.05)$. Only seven of 14 patients with gallstone achieved cholesterol unsaturation. In four patients with hypertriglyceridaemia and gallstones, mean unsaturation was produced and the saturation index changed from $1.70 \pm 0.45$ to $0.86 \pm 0.47(\mathrm{P}<0.05)$. When all nine patients with hypertriglyceridaemia were grouped, the mean saturation index fell from $1.52 \pm 0.40$ to $0.76 \pm 0.30$ after therapy $(\mathrm{P}<0.001)$. In contrast the 10 patients without hypertriglyceridaemia showed no significant fall in saturation index which was $1.50 \pm 0.54$ before and 1.24 \pm 0.40 after therapy. The ability of chenodeoxycholic acid feeding to improve bile saturation with cholesterol correlated with the presence of hypertriglyceridaemia whether or not gallstones were present. It did not correlate with gallstone dissolution or body weight.

It is known that bile from most patients with gallstones is characterised by an excessive amount of cholesterol (Isaksson, 1954; Admirand and Small, 1968; Mackay et al., 1972). Cholesterol oversaturation has been observed in subjects without gallstones (Heller and Bouchier, 1973; Holzbach et al., 1973; Northfield and Hofmann, 1973), but less frequently so. As a result of the observation that cholesterol gallstones could be dissolved by feeding chenodeoxycholic acid (Danzinger et al., 1972), it was suggested that fasting bile changes might uniformly be used to predict dissolution of stones (Iser et al., 1975) but this has not been the experience of ourselves or that of others (Northfield et al., 1973; James et al., 1975).

During the clinical monitoring of patients on chenodeoxycholic acid therapy it was observed that serum triglyceride levels were lowered, and as a result chenodeoxycholic acid has been suggested as a useful therapeutic agent in patients with hypertriglyceridaemia (Bell et al., 1973).

The present study was undertaken to ascertain whether there are differences between the response of

Received for publication 6 January 1977 groups of patients with gallstones, and with hypertriglyceridaemia but without gallstones, to prolonged therapy with chenodeoxycholic acid. There is little information on the effect of chenodeoxycholic acid in subjects without gallstones, and none on prolonged administration.

\section{Methods}

PATIENTS

Gallstones

Fourteen patients with gallstones agreed to take part in the trial of dissolution therapy with chenodeoxycholic acid. All gave informed consent. There were four men and 10 women with an age range of 34 to 86 years. All had functioning gallbladders containing stones shown at cholecystography: one also had common bile duct stones. Before starting treatment the patients attended fasting for the following blood investigations: cholesterol, triglycerides, cellulose acetate lipoprotein electrophoresis, aspartate aminotransferase, alkaline phosphatase, $\gamma$-glutamyl transpeptidase, bilirubin, albumin, total protein, calcium, phosphate, creatinine, urea, sodium, chloride, potassium, haemoglobin, white cell count, platelets, and blood film. Serum lipid patterns were classified after 
two separate determinations at constant weight (Technicon Autoanalyser technique).

After obtaining the blood samples a twin-lumen tube with radiopaque strip was screened into position in the second part of the duodenum. Bile-rich duodenal fluid was aspirated by intermittent suction for up to 20 minutes after cholecystokinin (Boots) 33 Ivy dog units intravenously. A preliminary dosage study indicated that this gave maximum cholecystokinesis while avoiding the frequent and severe reactions produced at higher levels. The most concentrated moiety as judged by inspection was saved for analysis.

Of the 14 patients with gallstones, six had normal serum lipids, four had pure hypercholesterolaemia (type IIa), two had pure hypertriglyceridaemia (type IV), and two had mixed hypercholesterolaemia and hypertriglyceridaemia (one type IV, one type IIb). Of these 14 patients, one with hypercholesterolaemia was on a low fat diet, and three with hypertriglyceridaemia were on low carbohydrate diets. The others were on no specific diets.

Patients were started and maintained on chenodeoxycholic acid $750 \mathrm{mg} /$ day. Though change in bowel habit was frequent, none developed persistent troublesome diarrhoea. They were followed at monthly intervals for repeat blood tests as above. All patients were reintubated after exactly six months' treatment and a further sample of duodenal juice obtained. Cholecystograms were usually repeated at six-monthly intervals, and all patients were followed up for at least a year.

\section{Hypertriglyceridaemia with or without hypercholesterolaemia}

Six consecutive patients with normal cholecystograms in whom dietary therapy had failed to control hypertriglyceridaemia with or without hypercholesterolaemia were referred for treatment with chenodeoxycholic acid, in an attempt to lower their serum triglycerides. All were started on chenodeoxycholic acid $750 \mathrm{mg}$ daily. In one patient diarrhoea necessitated a dose reduction to $500 \mathrm{mg} /$ day and he is not included in the study. The patients were monitored and intubated as above.

These five patients were on a low carbohydrate diet and three of them were also on a low fat diet. Three of these patients had pure hypertriglyceridaemia (type IV) and two mixed hypertriglyceridaemia and hypercholesterolaemia (one type IIb, one type IV). They formed part of a group of 13 patients with hypertriglyceridaemia who received chenodeoxycholic acid 500 to $750 \mathrm{mg}$ daily for six months.

TECHNIQUES

The majority of samples were processed on the day of intubation. With a few samples it was necessary to store by freezing at $-20^{\circ} \mathrm{C}$. An aliquot of bile was extracted by Folch technique and analysed for phospholipid as detailed elsewhere (Murison et al., 1976).

Analysis for bile acids and cholesterol was conducted differently by a gas-liquid chromatography technique. Cholyl-glycine hydrolase $0.3 \mathrm{ml}$ (Nair et al., 1967) was added to a test tube containing $0.1 \mathrm{ml}$ thoroughly mixed duodenal aspirate, $0.8 \mathrm{ml}$ Sorensen's buffer pH $5 \cdot 6$, and $20000 \mathrm{dpm}{ }^{3} \mathrm{H}$ glycocholic acid as tracer. The tubes were stoppered immediately and incubated at $37^{\circ} \mathrm{C}$ for one hour. The incubation was stopped with the addition of $0 \cdot 1$ $\mathrm{ml} 6 \mathrm{~N} \mathrm{HCl}$, and extracted thrice with $1 \mathrm{ml}$ ethyl acetate: the mixture was agitated on a Whirlimixer and centrifuged for five minutes at $3000 \mathrm{rpm}$. The top layers were bulked, dried down by rotary evaporator, and then taken up in $0.5 \mathrm{ml}$ methanol. The method of Klaassen (1971) was then followed.

Diazomethane was prepared freshly daily. Nmethyl-N-nitroso-p-toluene sulphonamide (Diazold) $6.4 \mathrm{~g}$ was placed in a $250 \mathrm{ml}$ round-bottomed flask immersed in ice and dissolved in $90 \mathrm{ml}$ diethyl ether. To this was carefully added $30 \mathrm{ml}$ ethanol containing $1.2 \mathrm{~g}$ potassium hydroxide. The solution was allowed to cool for 10 minutes and then distilled cautiously using minimum heat. The distillate was collected in a tube immersed in ice. This reagent, $0.5 \mathrm{ml}$, was used to methylate the bile lipid extract, further diazomethane being added dropwise if decolorisation occurred. The solution was dried down under nitrogen and an internal standard of $100 \mu \mathrm{g}$ stigmasterol added. Trifluoracetic acid (BDH), $0.2 \mathrm{ml}$, was added and the mixture incubated for one hour at $60^{\circ} \mathrm{C}$, and then dried down under nitrogen. Ethyl acetate, $0.1 \mathrm{ml}$, was added immediately before injection into a GLC column ( $1 \%$ OV 210 on GasChrom Q).

Reference standards of TFA chenodeoxycholic, cholic, deoxycholic, lithocholic, and ursodeoxycholic methyl esters and TFA cholesterol were used to identify and quantify peaks.

Good reproducibility was obtained. For seven pairs of duplicate samples the coefficient of variation for cholesterol was $2 \cdot 17$, and the coefficient between samples $r=0.98$. For the individual bile acids the figures were respectively: lithocholate $8 \cdot 12, r=0.94$; deoxycholate $1 \cdot 56, r=0.99$; chenodeoxycholate 4.00 , $r=0.99$; cholate $1.85, r=0.99$; and ursodeoxycholate 5.00, $r=0.99$.

The individual bile lipids were expressed in molar concentration as a percentage of the total molar concentration of cholesterol, bile acid, and cholesterol. Bile acids were taken as the sum of the five individual components measured. These were cholic, 
deoxycholic, chenodeoxycholic, ursodeoxycholic, and lithocholic acids. No other bile acid was detected in significant amounts.

Results were calculated according to the polynomial formula of Thomas and Hofmann (1973) to derive the saturation index from the data of Admirand and Small (1968) and also the 'lithogenic' index from the data of Holzbach (1973) and Hegardt and Dam (1971). A saturation index of greater than 1 indicates bile definitely oversaturated with cholesterol. A saturation index of less than 1 indicates bile with less cholesterol than usually found. In our laboratory the mean saturation index of 39 patients without gallstones was 1.03. A 'lithogenic' index is derived so that at less than 1 it indicates complete chemical stability of cholesterol solution. The data were also plotted on triangular co-ordinates and the molar ratios of cholesterol to bile acid plus phospholipid calculated. Differences were examined by Student's paired and unpaired $t$ tests and Wilcoxon paired and unpaired rank sum tests as appropriate.

\section{Results}

\section{BILIARY LIPIDS}

There were no significant differences in the biliary lipids of patients with and without gallstones before therapy (Table 1).

There was a significant qualitative difference between the response to chenodeoxycholic acid of 14 patients with gallstones and the five patients without. Only seven of 14 of the patients with gallstone achieved unsaturation of bile even on the criteria of Admirand and Small (1968). All of the patients without gallstones achieved unsaturation of bile by this standard: this was associated with a significant fall in the proportion of cholesterol and a significant rise in that of bile acid. Body weight and dosage were comparable in the two groups.
The patients with gallstones were divided into groups according to their serum lipid pattern. One in four patients with pure hypercholesterolaemia achieved unsaturation, but the mean saturation index for the group was $1.21 \pm 0.24$ before and $1.24 \pm 0.24$ after therapy. Of six patients with normal serum lipids three achieved unsaturated bile; the mean saturation index was $1.69 \pm 0.64$ before and $1.24 \pm 0.48$ after therapy. The four patients with hypertriglyceridaemia were different. In three unsaturation occurred, and the mean saturation index fell to unsaturated levels (from $1 \cdot 70$ to $0 \cdot 86$, Table 2).

When these four patients with hypertriglyceridaemia and gallstones were compared with the five patients with hypertriglyceridaemia but without gallstones, the values for biliary lipids were similar both before and after treatment (Table 2).

Therefore results for all nine patients with raised serum triglycerides (mean value $3.34 \mathrm{mmol}$ ) were pooled and compared with the 10 patients without hypertriglyceridaemia (mean $1.59 \mathrm{mmol}$ ). There were seven men in the first group and one man in the second group. The mean weight of the patients with hypertriglyceridaemia was greater, but this did not achieve statistical significance. The absence of effect of chenodeoxycholic acid therapy in the patients without hypertriglyceridaemia could not have resulted from smaller dosage/unit body weight. Of the nine patients with hypertriglyceridaemia, eight achieved unsaturated bile, the mean saturation index falling significantly from 1.52 to $0.76(\mathrm{P}<0.001$, Table 3). No such significant change occurred in the other group without hypertriglyceridaemia. There was a correlation between the final saturation index and the pretreatment serum triglyceride level $(r=0.60, t 3.09, \mathrm{P}=<0.01)$, though there was no correlation at all between the initial saturation index and this triglyceride level $(r=0.04)$.

In the four patients on a low fat regimen through-

Table 1 Biliary lipids before and after six months therapy with chenodeoxycholic acid $750 \mathrm{mg} /$ day

\begin{tabular}{|c|c|c|c|c|c|c|c|}
\hline \multirow[t]{2}{*}{ Patients } & \multirow[t]{2}{*}{ Cholesterol } & \multirow[t]{2}{*}{ Phospholipid } & \multirow[t]{2}{*}{ Total bile acids } & \multirow[t]{2}{*}{ Molar ratio } & \multicolumn{2}{|l|}{ Index } & \multirow{2}{*}{$\begin{array}{l}\text { Mean } \\
\text { weight } \\
\text { (dose) }\end{array}$} \\
\hline & & & & & Saturation & 'Lithogenic' & \\
\hline \multicolumn{8}{|c|}{ With gallstones (14) } \\
\hline $\begin{array}{l}\text { Before } \\
\text { After }\end{array}$ & $\begin{array}{l}13 \cdot 62 \pm 4 \cdot 50 \\
10 \cdot 54 \pm 4 \cdot 23 \\
\text { (NS) }\end{array}$ & $\begin{array}{l}17.29 \pm 10.03 \\
18.91 \pm 8.11 \\
(N S)\end{array}$ & $\begin{array}{l}69.08 \pm 12.93 \\
70.44 \pm 9.63 \\
\text { (NS) }\end{array}$ & $\begin{array}{l}7 \cdot 60 \pm 2 \cdot 89 \\
9 \cdot 68 \pm 4 \cdot 34 \\
(N S)\end{array}$ & $\begin{array}{l}1.55 \pm 0.52 \\
1.13 \pm 0.43 \\
(P<0.05)\end{array}$ & $\begin{array}{l}2.45 \pm 0.88 \\
1.83 \pm 0.72 \\
(P<0.025)\end{array}$ & $\begin{array}{l}69 \cdot 1 \mathrm{~kg}(55-96 \mathrm{~kg}) \\
(10 \cdot 85 \mathrm{mg} / \mathrm{kg})\end{array}$ \\
\hline \multicolumn{8}{|c|}{ With gallstones (5) } \\
\hline $\begin{array}{l}\text { Before } \\
\text { After }\end{array}$ & $\begin{array}{c}13.04 \pm 3.12 \\
6.58 \pm 0.72 \\
(P<0.005)\end{array}$ & $\begin{array}{l}23 \cdot 12 \pm 9.85 \\
18.18 \pm 3.32 \\
\text { (NS) }\end{array}$ & $\begin{array}{l}63.82 \pm 8.28 \\
75.23 \pm 3.75 \\
(P<0.002)\end{array}$ & $\begin{array}{l}6.95 \pm 1.51 \\
14.26 \pm 1.61 \\
(P<0.001)\end{array}$ & $\begin{array}{l}1.38 \pm 0.31 \\
0.68 \pm 0.00 \\
(P<0.005)\end{array}$ & $\begin{array}{l}1.99 \pm 0.17 \\
1.13 \pm 0.14 \\
(P<0.05)\end{array}$ & $\begin{array}{l}68 \mathrm{~kg}(52-74 \mathrm{~kg}) \\
(11.02 \mathrm{mg} / \mathrm{kg})\end{array}$ \\
\hline
\end{tabular}

Differences examined by Student's paired $t$ test.

Lipid results expressed as molar percentage of total lipids $( \pm$ SD)

Molar ratio $=\frac{\text { Total bile acids }(\mathbf{M})+\text { phospholipid }(\mathbf{M})}{\text { Cholesterol }(\mathbf{M})}$ 
Table 2 Biliary lipids before and after six months' therapy with chenodeoxycholic acid $750 \mathrm{mg} /$ day (mol \%): patients with hypertriglyceridaemia, with and without gallstones

\begin{tabular}{|c|c|c|c|c|c|c|}
\hline \multirow[t]{2}{*}{ Patients } & \multirow[t]{2}{*}{ Cholesterol } & \multirow[t]{2}{*}{ Phospholipid } & \multirow[t]{2}{*}{ Total bile acids } & \multirow[t]{2}{*}{ Molar ratio } & \multicolumn{2}{|l|}{ Index } \\
\hline & & & & & Saturation & 'Lithogenic' \\
\hline \multicolumn{7}{|l|}{ Before } \\
\hline With gallstones (4) & $16 \cdot 42 \pm 4 \cdot 10$ & $18 \cdot 58 \pm 6 \cdot 18$ & $64.99 \pm 7.03$ & $5 \cdot 37 \pm 1 \cdot 57$ & $1.70 \pm 0.45$ & $2.61 \pm 1.09$ \\
\hline Without gallstones (5) & $13 \cdot 40 \pm 3 \cdot 12$ & $23 \cdot 12 \pm 9 \cdot 85$ & $63 \cdot 82 \pm 8 \cdot 28$ & $6.95 \pm 1.51$ & $1.38 \pm 0.31$ & $1.99 \pm 0.17$ \\
\hline \multicolumn{7}{|l|}{ After } \\
\hline With gallstones (4) & $8 \cdot 35 \pm 5 \cdot 07$ & $17 \cdot 84 \pm 5.98$ & $73 \cdot 80 \pm 9 \cdot 46$ & $13.49 \pm 5.58$ & $0.86 \pm 0.47$ & $1.41 \pm 0.65$ \\
\hline Without gallstones (5) & $6.58 \pm 0.72$ & $18 \cdot 18 \pm 3 \cdot 32$ & $75 \cdot 23 \pm 3 \cdot 75$ & $14.26 \pm 1 \cdot 61$ & $0.68 \pm 0.00$ & $1 \cdot 13 \pm 0.14$ \\
\hline
\end{tabular}

Differences examined by Student's unpaired $t$ test.

Table 3 Biliary lipids before and after six month' therapy with chenodeoxycholic acid $750 \mathrm{mg} /$ day (mol \%)

\begin{tabular}{|c|c|c|c|c|c|c|c|}
\hline \multirow[t]{2}{*}{ Patients } & \multirow[t]{2}{*}{ Cholesterol } & \multirow[t]{2}{*}{ Phospholipid } & \multirow[t]{2}{*}{ Total bile acids } & \multirow[t]{2}{*}{ Molar ratio } & \multicolumn{2}{|l|}{ Index } & \multirow{2}{*}{$\begin{array}{l}\text { Mean } \\
\text { weight } \\
\text { (dose) }\end{array}$} \\
\hline & & & & & Saturation & 'Lithogenic' & \\
\hline \multicolumn{8}{|c|}{$\begin{array}{l}\text { With } \\
\text { hypertriglyceridaemia (9) }\end{array}$} \\
\hline $\begin{array}{l}\text { Before } \\
\text { After }\end{array}$ & $\begin{array}{c}14.54 \pm 3.79 \\
7.36 \pm 3.29 \\
(P<0.001)\end{array}$ & $\begin{array}{l}21 \cdot 10 \pm 8 \cdot 28 \\
18 \cdot 33 \pm 4 \cdot 35 \\
\text { (NS) }\end{array}$ & $\begin{array}{l}64.34 \pm 7.29 \\
76.60 \pm 6.38 \\
(P<0.01)\end{array}$ & $\begin{array}{l}6.25 \pm 1.66 \\
13.99 \pm 3.62 \\
(P<0.001)\end{array}$ & $\begin{array}{l}1.52 \pm 0.40 \\
0.76 \pm 0.30 \\
(P<0.001)\end{array}$ & $\begin{array}{l}2 \cdot 26 \pm 0.96 \\
1 \cdot 25 \pm 0.44 \\
(P<0.001)\end{array}$ & $\begin{array}{l}71 \cdot 7 \mathrm{~kg}(55-90 \mathrm{~kg}) \\
(10.46 \mathrm{mg} / \mathrm{kg})\end{array}$ \\
\hline \multicolumn{8}{|c|}{$\begin{array}{l}\text { Without } \\
\text { hypertriglyceridaemia (10) }\end{array}$} \\
\hline $\begin{array}{l}\text { Before } \\
\text { After }\end{array}$ & $\begin{array}{l}12.50 \pm 4.33 \\
11.42 \pm 3.78 \\
\text { (NS) }\end{array}$ & $\begin{array}{l}16 \cdot 78 \pm 11 \cdot 47 \\
19 \cdot 34 \pm 9.07 \\
\text { (NS) }\end{array}$ & $\begin{array}{l}70 \cdot 71 \pm 14 \cdot 67 \\
69 \cdot 10 \pm 9 \cdot 84 \\
\text { (NS) }\end{array}$ & $\begin{array}{l}8 \cdot 49 \pm 2 \cdot 85 \\
8 \cdot 16 \pm 2 \cdot 79 \\
(N S)\end{array}$ & $\begin{array}{l}1.50 \pm 0.54 \\
1.24 \pm 0.40 \\
\text { (NS) }\end{array}$ & $\begin{array}{l}2 \cdot 38 \pm 0.84 \\
2.00 \pm 0.70 \\
(N S)\end{array}$ & $\begin{array}{l}66 \cdot 2 \mathrm{~kg}(55-96 \mathrm{~kg}) \\
(11.32 \mathrm{mg} / \mathrm{kg})\end{array}$ \\
\hline
\end{tabular}

Differences examined by Student's paired $t$ test.

out the study, a pronounced improvement occurred in the bile of each (SI 1.49 $\rightarrow 0.99,1.35 \rightarrow 0.77,1.22 \rightarrow$ $0.63,1 \cdot 36 \rightarrow 0 \cdot 60$ ).

\section{SERUM LIPIDS}

Cholesterol levels did not change, nor did normal triglyceride levels. In 13 patients with hypertriglyceridaemia treated with chenodeoxycholic acid 750 $\mathrm{mg} /$ day (12) or $500 \mathrm{mg} /$ day (one), the serum triglycerides fell from $3.56 \pm 0.99$ to $3.03 \pm 0.83 \mathrm{mmol}$ $(\mathrm{P}<0.05)$ over six months.

\section{INDIVIDUAL BILE ACIDS}

In every case there was an increase in chenodeoxycholic acid and its metabolites after therapy, and a decrease in cholic acid and its metabolite (Table 4). Not all bile contained detectable amounts of ursodeoxycholic acid even after therapy. In nine patients it appeared for the first time after treatment with cheodeoxycholic acid, but in three it was not detected in either sample.

There was significantly more lithocholic acid in the bile of gallstone patients after therapy (6.61 \pm 4.42 compared with $3.41 \pm 1.33 \mathrm{~mol} / \mathrm{dl}, \mathrm{P}<0.02)$ but no other differences before or after therapy.

There was no significant difference in the proportions of bile acids between patients with and without hypertriglyceridaemia.

\section{DISSOLUTION}

The gallstones of three patients completely dissolved, as evidenced by two consecutive normal oral cholescystograms. One of these achieved bile unsaturation (SI 1.63 $\rightarrow 0.71$, cholesterol 11.90 $\rightarrow$ $7 \cdot 18 \mathrm{~mol} \%$ ). However, two became more saturated after therapy (SI $1.20 \rightarrow 1.46$ and $1.27 \rightarrow 1.47$, cholesterol $11.77 \rightarrow 14.79 \mathrm{~mol} \%$ and $12.07 \rightarrow 13.43$ $\mathrm{mol} \%$ ).

\section{Discussion}

The purpose of the present study was to compare the response of biliary lipids of patients with and without gallstones to chenodeoxycholic acid therapy. It 
Table 4 Individual bile acids as percentage of total bile acids ( $\mathrm{mol} \%$ )

\begin{tabular}{|c|c|c|c|c|c|}
\hline & Cholate & Deoxycholate & Chenodeoxycholate & Lithocholate & Ursodeoxycholate \\
\hline $\begin{array}{l}\text { All gallsto } \\
\text { Before } \\
\text { After }\end{array}$ & $\begin{array}{c}29.73 \pm 11.82 \\
7.56 \pm 7.89 \\
(P<0.001)\end{array}$ & $\begin{array}{l}29.45 \pm 21.32 \\
7.82 \pm 9.75 \\
(P<0.005)\end{array}$ & $\begin{array}{l}39.90 \pm 13.43 \\
74.40 \pm 16.89 \\
(P<0.001)\end{array}$ & $\begin{array}{l}3.01 \pm 1.62 \\
6.61 \pm 4.42 \\
(P<0.01)\end{array}$ & $\begin{array}{l}2 \cdot 87 \pm 5 \cdot 59 \\
3 \cdot 18 \pm 2 \cdot 62 \\
\text { (NS) }\end{array}$ \\
\hline $\begin{array}{l}\text { Hypertrigl } \\
\text { stones (5) } \\
\text { Before } \\
\text { After }\end{array}$ & $\begin{array}{l}23.65 \pm 8.48 \\
5.10 \pm 3.73 \\
(P<0.01)\end{array}$ & $\begin{array}{l}27.51 \pm 5.54 \\
6.31 \pm 5.61 \\
(\mathrm{P}<0.01)\end{array}$ & $\begin{array}{l}45.17 \pm 12.59 \\
82.41 \pm 9.87 \\
(P<0.01)\end{array}$ & $\begin{array}{l}2.09 \pm 0.94 \\
3.41 \pm 1.33 \\
\text { (NS) }\end{array}$ & $\begin{array}{l}1.55 \pm 2.31 \\
2.75 \pm 1.37 \\
\text { (NS) }\end{array}$ \\
\hline
\end{tabular}

Differences examined by Wilcoxon's paired rank sum test.

Table 5 Initial bile acid composition of nine patients with and 10 without hypertriglyceridaemia (mol $\%$ total bile acid)

\begin{tabular}{llllll}
\hline & Cholate & Deoxycholate & Chenodeoxycholate & Lithocholate & Ursodeoxycholate \\
\hline Hypertriglyceridaemia (9) & $22.40 \pm 6.49$ & $29.57 \pm 9.07$ & $42.25 \pm 11.52$ & $2.55 \pm 1.47$ & $3.21 \pm 3.52$ \\
All others(10) & $33.29 \pm 12.20$ & $20.06 \pm 16.16$ & $39.01 \pm 14.97$ & $2.96 \pm 1.60$ & $1.90 \pm 6.02$ \\
\hline
\end{tabular}

No significant differences by Wilcoxon's unpaired rank sum test.

was observed that important differences in response to treatment occurred, which related more to the serum lipid pattern than to the presence of gallstones.

It is established that fasting gallbladder and hepatic bile in Western countries is frequently oversaturated with cholesterol (Heller and Bouchier, 1973; Holzbach et al., 1973; Northfield and Hofmann, 1973). In addition, diurnal rhythms of hepatic bile composition are of crucial importance in determining lithogenicity (Smallwood et al., 1972; Metzger et al., 1973).

It is not necessarily significant that the five patients without gallstones and with hypertriglyceridaemia had oversaturated bile. Our experience is that serum lipid patterns do not correlate with biliary lipid composition, though obesity (Freeman et al., 1975) and treatment of lipid disorders may well do so (Grundy et al., 1972; Einarsson et al., 1973; Grundy, 1975).

In response to therapy the bile of patients with gallstones did not achieve mean unsaturation, whereas in patients without gallstones mean unsaturation was produced. When all patients with hypertriglyceridaemia were examined as a group, they showed a uniformly good response to feeding with chenodeoxycholic acid, and this was not related to the presence of gallstones or to the effectiveness of dissolution treatment. This accords with previous work performed elsewhere (James et al., 1975), but others suggest that biliary lipid analysis is helpful in prediction of dissolution (Iser et al., 1975).

No patients were taking clofibrate, nicotinic acid, or oral contraceptives during the period of study. There were no significant weight changes on therapy. Though four patients were on a low fat regimen throughout the study, this did not prevent a distinct improvement in bile in all of them. There was no significant difference in the dosage of patients with or without gallstones $(10.85$ compared with $11.02 \mathrm{mg} /$ $\mathrm{kg})$, nor in the dosage of patients with or without hypertriglyceridaemia (10.46 compared with 11.32 $\mathrm{mg} / \mathrm{kg}$ ). The dose of chenodeoxycholic acid used $(750 \mathrm{mg} /$ day) has been found sufficient to induce changes consistently in bile by others (Mok et al., 1974), and there is no reason to suppose that higher doses would have produced a qualitatively different answer.

There has been some dispute as to the exact criteria for definition of the hyperlipidaemias. Serum lipids do not have a normal distribution in the population, nor is there a bimodal distribution with clear separation, and therefore separation of 'normal' and 'raised' levels is necessarily arbitrary (Fredrickson, 1975). The same cut-off level for serum triglycerides, $2.48 \mathrm{mmol}$, was used for both sexes and this accords with current thought (Tabaqchali et al., 1974; Fredrickson, 1975). The mean triglyceride level in the group under study with hypertriglyceridaemia was clearly well in excess of this upper limit. Men were over-represented among patients with hypertriglyceridaemia, and this is to be expected in the community.

There are no consistently reported differences in the bile of patients with various patterns of hyper- 
lipidaemia or with normal serum lipids. Obesity is often associated with raised serum triglycerides, and in extreme cases is linked with excessive production of cholesterol (Miettinen, 1971) and uniform cholesterol oversaturation of bile $(13.0 \pm 0.7 \mathrm{~mol} / \mathrm{dl})$ compared with controls $(6.6 \pm 0.5 \mathrm{~mol} / \mathrm{dl})$ (Freeman et al., 1975). As serum triglycerides parallel total body production of cholesterol (Sodhi and Kudchodkar, 1973), whereas serum cholesterol levels do not (Miettinen, 1971; Sodhi and Kudchodkar, 1973), a logical connection may be seen between enhanced synthesis and enhanced excretion by the main pathway. Differences in weight were not observed between our patients with or without hypertriglyceridaemia, so this was not a factor.

Studies by others into the bile acid metabolism of patients with hyperlipidaemia have shown that the major differences in bile acid metabolism are the increased synthesis and pool of cholic acid and total bile acids in hypertriglyceridaemia (type IV, Fredrickson et al., 1967) and a decreased synthesis and pool of cholic acid and total bile acids $(50 \%)$ in hypercholesterolaemia (type IIa, Beaumont et al., 1970) (Einarsson and Hellstrom, 1972; Einarsson et al., 1974).

It is likely, but not yet proven, that this relates to differences in the activity of the rate-limiting liver enzymes responsible for cholesterol and bile acid synthesis in the liver. Both $\beta$-hydroxymethylglutarylcoenzyme A reductase and cholesterol $7 \alpha$-hydroxylase might be expected to be more active in hypertriglyceridaemia, as both body synthesis of cholesterol and of bile acids is increased. It could be that there is a greater potential for inhibition of HMGCoA reductase, and hence cholesterol output in bile, in hypertriglyceridaemia. Conversely, liver cholesterol synthesis and HMGCoA reductase activity may possibly below in hypercholesterolaemia (Einarsson and Hellström, 1972), which would limit the scope for effective inhibition.

It seems that biliary lipid response to bile acid feeding is determined by factors which also influence systemic lipid metabolism. This may account for some of the observed failures of response to dissolution therapy.

The bile acid patterns showed only one striking finding before therapy-a smaller proportion of cholic acid in the bile of patients with hypertriglyceridaemia $(22.40 \pm 6.49 \%)$ than in the others $(33.29 \pm 12.20 \%$ statistical significance. Patients with gallstones were not found to be significantly different from patients without gallstones in this study.

In response to feeding with chenodeoxycholic acid the expected increase occurred in the proportion of biliary chenodeoxycholic acid and its metabolites, and decrease in cholic and deoxycholic acid occurred. This did not correlate with changes in the cholesterol saturation of bile nor was it a prerequisite of dissolution.

In gallstone disease about one-third of the lithocholic acid is sulphated and this increases to threequarters after chenodeoxycholic acid therapy (Stiehl et al., 1975). Our GLC technique measured only unsulphated lithocholic acid, so changes in bile lithocholate levels may be of even greater magnitude than documented here (Table 4). The proportion of lithocholate sulphated after chenodeoxycholic acid feeding would be unlikely to depend on the presence of gallstone or on serum lipid patterns.

We conclude that there is a relationship between systemic triglyceride metabolism and biliary lipids, which governs response to chenodeoxycholic therapy. This does not depend on the presence of gallstones, which is itself not a predictor of response. These findings are of prime importance in the monitoring of bile in the management of gallstone dissolution therapy.

Miss A. McDonald and Miss K. Taylor gave expert technical assistance. M.C.B. was in receipt of a grant from Weddel Pharmaceuticals Ltd., who generously supplied the chenodeoxycholic acid without charge. I.A.D.B. is in receipt of a grant from the Medical Research Council.

\section{References}

Admirand, W., and Small, D. M. (1968). Physiochemical basis of cholesterol gallstone formation in man. Journal of Clinical Investigation, 47, 1043-1052.

Angelin, B., Einarsson, K., and Hellström, K. (1976). Evidence for the absorption of bile acids in the proximal small intestine of normo- and hyperlipidaemic subjects. Gut, 17, 420-425.

Beaumont, J. L., Carlson, L. A., Cooper, G. R., Fejfar, Z., Fredrickson, D. S., and Strasser, T. (1970). Classification of hyperlipidaemias and hyperlipoproteinaemias. Bulletin of the W.H.O., 43, 891-908.

Bell, G. D., Lewis, B., Petrie, A., and Dowling, R. H. (1973). Serum lipids in cholelithiasis: effect of chenodeoxycholic acid therapy. British Medical Journal, 3, 520-523.

Cahlin, E., Jönsson, J., Nilsson, S., and Scherstén, T. (1973). Biliary lipid composition in normolipidemic and pre- $\beta$ hyperlipoproteinemic gallstone patients. Scandinavian Journal of Gastroenterology, 8, 449-456.

Danzinger, R. G., Hofmann, A. F., Schoenfield, L. J., and Thistle, J. L. (1972). Dissolution of cholesterol gallstones with chenodeoxycholic acid. New England Journal of Medicine, 286, 1-8.

Einarsson, K., and Hellström, K. (1972). The formation of bile acids in patients with three Types of hyperlipoproteinaemia. European Journal of Clinical Investigation, 2, 225230.

Einarsson, K., Hellström, K., and Kallner, M. (1973). The effect of clofibrate on the elimination of cholesterol as b'le acids in patients with hyperlipoproteinaemia Type II and IV. European Journal of Clinical Investigation, 3, 345-351. 
Einarsson, K., Hellström, K., and Kallner, M. (1974). Bile acid kinetics in relation to sex, serum lipids, body weights and gallbladder disease in patients with various types of hyperlipoproteinemia. Journal of Clinical Investigation, 54, 1301-1311.

Fredrickson, D. S. (1975). It's time to be practical. Circulation, 51, 209-211.

Fredrickson, D. S., Levy, R. I., and Lees, R. S. (1967). Fat transport in lipoproteins-an integrated approach to mechanisms and disorders. New England Journal of Medicine, 276, 34-44, 94-103, 148-156, 215-225, 273-281.

Freeman, J. B., Meyer, P. D., Printen, K. J., Mason, E. E. and DenBesten, L. (1975). Analysis of bile in morbid obesity. American Journal of Surgery, 129, 163-166.

Grundy, S. M. (1975). Effects of polyunsaturated fats on lipid metabolism in patients with hypertriglyceridemia. Journal of Clinical Investigation, 55, 269-282.

Grundy, S. M., Ahrens, E. H., Salen, G., Schreibman, P. H., and Nestel, P. J. (1972). Mechanisms of action of clofibrate on cholesterol metabolism in patients with hyperlipidemia. Journal of Lipid Research, 13, 531-551.

Hegardt, F. G., and Dam, H. (1971). The solubility of cholesterol in aqueous solutions of bile salts and lecithin. Zeitschrift für Ernährungswissenschaft, 10, 223-233.

Heller, F., and Bouchier, I. A. D. (1973). Cholesterol and bile salt studies on the bile of patients with cholesterol gallstones. Gut, 14, 83-88.

Holzbach, R. T., Marsh, M., Olszewski, M., and Holan, K. (1973). Cholesterol solubility in bile. Evidence that supersaturated bile is frequent in healthy man. Journal of Clinical Investigation, 52, 1467-1479.

Isaksson, B. (1954). On the lipid constituents of bile from human gallbladder containing cholesterol gallstones. A comparison with normal human bladder bile. Acta Societatis Medicorum Upsaliensis, 59, 277-295.

Iser, J. H., Dowling, R. H., Mok, H. Y. I., and Bell, G. D. (1975). Chenodeoxycholic acid treatment of gallstones-a follow-up report and analysis of factors influencing response to therapy. New England Journal of Medicine, 293, 378-383.

James, O., Cullen, J., and Bouchier, I. A. D. (1975). Chenodeoxycholic acid therapy for gallstones: effectiveness, toxicity and influence on bile acid metabolism. Quarterly Journal of Medicine, 44, 349-367.

Klaassen, C. D. (1971). Gas-liquid chromatographic deter- mination of bile acids in bile. Clinica Chimica Acta, 35, 225-229.

Mackay, C., Crook, J. N., Smith, D. C., and McAllister, R. A. (1972). The composition of hepatic and gallbladder bile in patients with gallstones. Gut, 13, 759-762.

Metzger, A. L., Adler, R., Heymsfield, S., and Grundy, S. M. (1973). Diurnal variation in biliary lipid composition. New England Journal of Medicine, 288, 333-336.

Miettinen, T. A. (1971). Cholesterol production in obesity. Circulation, 44, 842-850.

Mok, H. Y. I., Bell, G. D., and Dowling, R. H. (1974). The effects of different doses of chenodeoxycholic acid and withdrawing treatment on bile lipid composition and liver function in patients with gallstones. Gut, 15, 340 .

Murison, J., Festi, D., Ross, P. E., and Bouchier, I. A. D. (1976). The estimation of phospholipids in bile. Clinica Chimica Acta, 68, 159-166.

Nair, P. P., Gordon, M., and Reback, J. (1967). The enzymatic cleavage of the carbon-nitrogen bond in $3 a, 7 a, 12 \alpha-$ trihydroxy-5 $\beta$-cholan-24-oylglycine. Journal of Biological Chemistry, 242, 7-11

Northfield, T. C., and Hofmann, A. F. (1973). Biliary lipid secretion in gallstone patients. Lancet, 1, 747-748.

Northfield, T. C., LaRusso, N. F., Thistle, J. L., and Hofmann, A. F. (1973). Effect of chenodeoxycholic acid therapy on biliary lipid secretion in gallstone patients. Gastroenterology, 64, 780.

Smallwood, R. A., Jablonski, P., and Watts, J. McK. (1972). Intermittent secretion of abnormal bile in patients with cholesterol gallstones. British Medical Journal, 4, 263-266.

Sodhi, H. S., and Kudchodkar, B. J. (1973). Correlating metabolism of plasma and tissue cholesterol with that of plasmalipoproteins. Lancet, 1, 513-519.

Stiehl, A., Raedsch, R., and Kommerell, B. (1975). Increased sulfation of lithocholate in patients with cholesterol gallstones during chenodeoxycholate treatment. Digestion, 12, 105-110.

Tabaqchali, S., Chait, A., Harrison, R., and Lewis, B. (1974). Experience with simplified scheme of treatment of hyperlipidaemia. British Medical Journal, 3, 377-380.

Thomas, P. J., and Hofmann, A. F. (1973). A simple calculation of the lithogenic index of bile: expressing biliary lipid composition on rectangular co-ordinates. (Correspondence). Gastroenterology, 65, 698-700. 